\title{
Is acute glaucoma a symptom of diabetes?
}

\author{
MICHAEL CLARKE AND JONATHAN JAGGER \\ From the Western Ophthalmic Hospital, London NW1
}

SUMMARY Forty-three patients who had suffered an episode of angle closure glaucoma had an assessment of glucose tolerance. Two patients were known diabetics and one new diabetic was found as a result of the study. The prevalence of diabetes in this series did not differ significantly from the normal in view of the age distribution of the patients.

It has recently been reported for the first time that there is a high prevalence of diabetes in patients with closed angle glaucoma.' From a total of 142 patients 24 were found to be diabetic, only seven of these having previously diagnosed diabetes. A further 29 were found to have impaired glucose tolerance. This was a significantly increased number relative to a control group.

These results suggest that there are large numbers of patients with closed angle glaucoma who have undiagnosed diabetes. It is obviously important that this diagnosis should be made, particularly as long term treatment with miotics may prejudice the diagnosis and assessment of diabetic retinopathy.

We have studied a group of patients with closed angle glaucoma to determine whether any have undiagnosed diabetes.

\section{Patients and methods}

A total of 50 patients who had suffered from angle closure glaucoma were asked to return for assessment of their glucose tolerance. Forty-three patients attended. Two of them were known to have diabetes, and this diagnosis was accepted.

The remaining 41 patients had blood taken for blood sugar and glycosylated haemoglobin estimations following an overnight fast. If either of these results was abnormal, they were asked to return for an oral glucose tolerance test. The normal value for fasting blood sugar was taken to be $\leqslant 6.4 \mathrm{mmol} / \mathrm{l}^{2}$ and that for glycosylated haemoglobin $<8 \cdot 0 \%{ }^{3}$

The oral glucose tolerance test was performed as laid down by the WHO committee guidelines. ${ }^{+}$That is, following an overnight fast blood was taken for

Correspondence to D M Clarke, Bradford Royal Infirmary, Bradford BD9 6RJ. fasting sugar estimation. A $75 \mathrm{~g}$ oral glucose load in $300 \mathrm{ml}$ of water was then given to be drunk within five minutes. Venous blood sugar estimations were made at one and two hours after the glucose load.

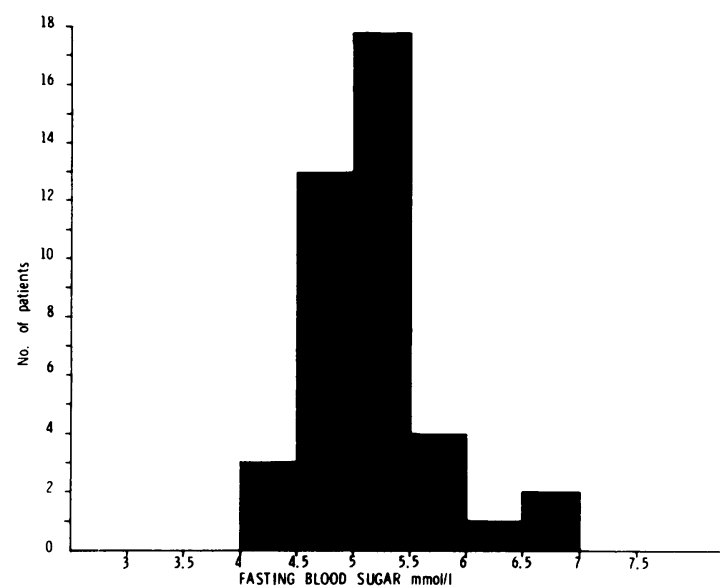

Fig. 1 Distribution of fasting blood sugar concentrations.

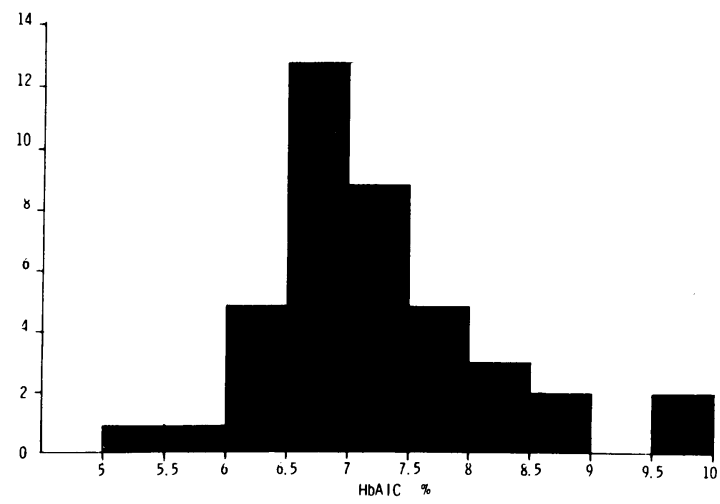

Fig. 2 Distribution of $\mathrm{HbA}_{l} \mathrm{C}$ values. 


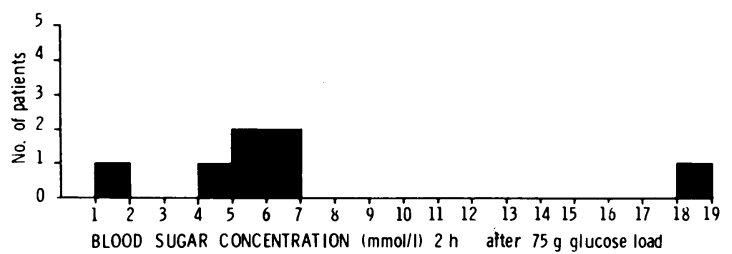

Fig. 3 Distribution of blood sugar concentration two hours after $75 \mathrm{~g}$ oral glucose load.

Diabetes was diagnosed if the fasting sugar was $\geqslant 8$ $\mathrm{mmol} / \mathrm{l}$ or the two-hour sugar was $\geqslant 11 \mathrm{mmol} / \mathrm{l}$. Impaired glucose tolerance was diagnosed if the fasting sugar was $<8 \mathrm{mmol} / \mathrm{l}$ and the two-hour specimen was $>8 \mathrm{mmol} / \mathrm{l}$ but $<11 \mathrm{mmol} / \mathrm{l}$.

\section{Results}

The fasting blood sugar levels are shown in Fig. 1. Two patients had fasting blood sugars $>6.4 \mathrm{mmol} / \mathrm{l}$ and proceeded to oral glucose tolerance testing. Five other patients had $\mathrm{HbA} 1_{\mathrm{c}}$ concentrations $>8 \%$ (Fig. 2 ). These too were given oral glucose tolerance tests-a total of seven patients. The two-hour blood sugar concentrations after oral glucose load are shown in Fig. 3. It can be seen that only one patient had an oral glucose tolerance test diagnostic of diabetes and that no other patient had diabetes or impaired glucose tolerance. The results are significantly different from those of Mapstone and Clark ${ }^{\prime}$ $\left(\chi^{2}=14, p<0 \cdot 001\right)$, when patients with both diabetes and impaired glucose tolerance are compared but not when only those with frank diabetes are compared $\left(\chi^{2}=2 \cdot 60\right)$.

\section{Discussion}

Only one patient in this series was found to have previously undiagnosed diabetes. Together with the two previously known diabetics this gives a prevalence of 6.99. This figure is compatible with the prevalence of diabetes among an unselected population of mixed Asian and European origin in West London, ${ }^{5}$ the area from which the patients in this

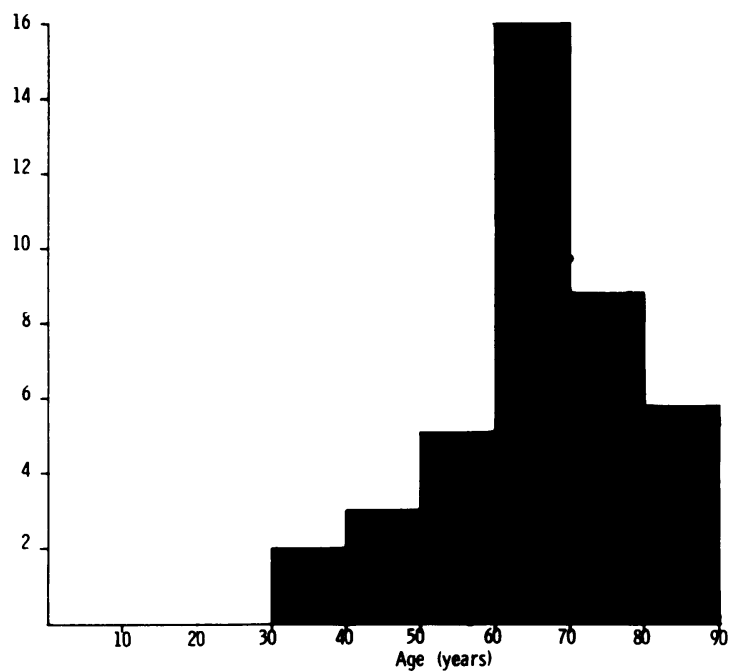

Fig. 4 Age distribution excluding two known diabetics.

series were drawn, when the age distribution of the series is taken into account (Fig. 4).

On the basis of this study it seems unlikely that screening for diabetes among patients with closed angle glaucoma will uncover many undiagnosed diabetics.

The authors are grateful to Professor R F Fisher for statistical help and to the consultant staff at the Western Ophthalmic Hospital for permission to study their patients.

\section{References}

1 Mapstone R, Clarke CV. Prevalence of diabetes in glaucoma. $\mathrm{Br}$ Med J 1985; 291: 93-5.

2 National Diabetes Data Group. Classification and diagnosis of diabetes and other forms of glucose intolerance. Diabetes 1979; 28: 1039-57.

3 Trivelli LA, Ranney HM, Hong-Tien L. Haemoglobin components in patients with diabetes mellitus. $N$ Engl J Med 1971; 284: 353-7.

4 WHO Expert Committee on Diabetes Mellitus. WHO Tech Rep Ser 1980: No.646.

5 Mather HM, Keen H. Southall diabetes survey. Br Med J 1985; 291: 1081-4.

Accepted for publication 7 March 1986. 